Volume and Issues Obtainable at Center for Sustainability Research and Consultancy
Journal of Business and Social Review in Emerging Economies
ISSN: 2519-089X \& ISSN (E): 2519-0326
Volume 7: Issue 3 September 2021
CSRᄃ
Journal homepage: www.publishing.globalcsrc.org/jbsee

\title{
Framework of a New Theory: Logistics Strategic Communication
}

Muhammad Wasil Solangi, RIPHAH International University Islamabad, Pakistan

Moazzam Naseer, Riphah International University Islamabad, Pakistan

*Rashid Farooq, RIPHAH International University Islamabad, Pakistan

*Corresponding author's email: rashedfarooq@ gmail.com

\begin{tabular}{l}
\hline ARTICLEDETAILS \\
\hline History \\
Revised format: Aug 2021 \\
Available Online: Sep 2021
\end{tabular}

\section{Keywords}

Logistics, $\quad$ Strategic

Communication,

Framework, Contextual Analysis, Logistics Strategic

Communication Theory

JEL Classification

D80, D83

\begin{abstract}
Objective: The goal of this research is to build up a determined model of creation that unequivocally sees the arising tasks and scenarios of logistics in getting over new hoarding frameworks and authoritative designs and legitimate plans that have made due to new serious market pressure and competitiveness with a framework of a new theory 'logistics strategic communication theory'.
\end{abstract}

Methodology: The research method used for this research paper is contextual analysis.

Findings: Logistics executives is a practice for organizations since it promotes competition and achieves improvements in the interest of the organizations. Logistics get combined into the general administration of the organization, bringing about a progression of data between various cycles and entertainers associated with the inventory network.

Implications: The presentation of ICT and the exceptional mechanical upheaval have made another serious climate, in light of the globalization of the economy and solid rivalry. Given this climate, organizations should confront making due in their areas, since it influences their worth chain. Hence, associations should overhaul their measures, figure out how to utilize ICT and speculations both unmistakable and elusive, to adjust to this new circumstance. Organizations, since it improves rivalry and accomplish enhancements in the benefit of them.

(02021The authors, under a Creative Commons AttributionNonCommercial 4.0

Recommended citation: Farooq, R., Solangi, M. W. and Naseer, M. (2021). Framework of a New Theory; Logistics Strategic Communication. Journal of Business and Social Review in Emerging Economies, 7(3), 527-535.

\section{Introduction}

Logistics management is incorporated inside the general administration of the organization, it manages the way toward arranging, activity and control of the development and capacity of products, just as administrations and the related progression of data, with the reason of dealing with the items from start to conveyance to the last buyer.Logistics is progressively significant for 
organizations as it is a strategy for them, and it moreover is turning into a significant factor to improve rivalry in a continually evolving market. The developing internationalization and globalization measure has prompted a further ascend in it. Particularly the developing distances between the partaking organizations bring about expanding issues in guaranteeing a generally effective also, powerful communication strategy at each value-added step. The equivalent applies to the data stream between the organizations associated with an inexorably mind boggling and worldwide logistic communication strategy. Communication from logistics to other department to other departments is important for instance if customer representative need to look into an order and need to update its status, they need to have real time access to logistics and if the sales department need to look in to the effectively of the sales to see how much sales have gone up. So, they also need access to the logistics. The communication process needs to be in real time, different departments need tohave a way of accessing the logistics information and then it needs to be concise and transparent for easier access.

\section{Literature Review}

Strategy is an essential matter for any organizational business. In these modernized times, it is concerning the failure or success of any sort of organization. Porter (1996), describes competitive strategy as building one or more competitive position that results in a superior and sustainable financial position. Also, strategy is described as the long-lasting objectives which create advantages in a constantly evolving business organization through the application of subsistence to deliver value in the business (Johnson, Whittington, \& Scholes, 2009).

The ever-evolving market trends and business models require business supervisors to generate tangible business strategies to provide their businesses a long-lasting competitive gain over their competitors. There is an escalating need to form strategic organizational strategies to efficiently compete. Mandy Mok Kin man (2009) states in his research paper that an organization needs a logistics approach to describe the fundamental procedure of behavior that they intend to pursue to accomplish their goals.

Barney (1991) postulated that an organization's success is estimated by the value it formulates by executing a unique strategy. This can be accomplished by employing its competencies, capabilities, and resources harmonized with the market opportunities given to produce a sustainable logistics advantage. Consequently, we can diminish from the definitions mentioned above that a strategy attempts to approach the sustainable administration of an organization. Secondly, a strategy should have opportunities for action that should be determined by the organization. Thirdly, the formulated strategy should provide the organization with logistic leverage over its rivals. The fourth policy is that a strategy should meet with the organization's business situation. Also, it should utilize the company's resources and competencies. And most importantly, a strategy should meet the expectations of the associates in the industry and within the company and generate value.

Harvard Business Review article (2015) states that, when formulating strategy, a long-lasting benefit can be produced by attempting the contribution mentioned below:

- A unique contribution by the organization

- Implementing projects that are adapted to the strategy

- Clear choices and trade-offs

- Operational effectiveness

Research by Klynveld Peat Marwick Goerdeler discovered that with the more elevated strategic advantage, associated with the logistics sector, a growing number of firms in the service industries, wholesale, retail, and manufacturing is building approved logistics communication strategies. (Hill, 1994). Hill (1996) and Muller (1994) explained that the effective administration of logistics function is important for businesses to compete victoriously in the expedited business 
setting. Strategic logistics communication should be combined with marketing, corporate, and production policies (Masters \& LaLonde, 1995). Also, logistics outlining should be blended with purchasing and operations (Fawcett \& Fawcett, 1995). Mixing logistics with other functional sectors will deliver the complete ability of the organizations' value-added pursuits and empower them to achieve a vital competing leverage over their rivals (Richardson H.L., 1995). Logistics communication strategies will also lead to an advancement in consumer service and a decrease in operational expense (Christopher, 1989).

\section{Framework}

The framework recommends that efficiency of production and performance will greatly increase of the firm's design and strategy is steady with the qualities natural in the company's coordination decisions which are the firm's logistics choices. To guarantee an effective progression of products and data the arrangement of the executives is turning out to be more flow-oriented and isn't restricted to the single organization itself, yet rather all deliberately significant providers, just as clients, must be incorporated in to the decision process. Following the idea of a flow-based process optimization, logistics is acquiring further significance as an instrument for guaranteeing a successful and productive progression of items. Along these lines, logistics is not, at this point restricted to the acknowledgment of employable vehicle, dealing with, and capacity exercises, however has arisen in terms of a flow-oriented administration as another administration worldview. (Chan, Shi, \& Wang, 2007).

\section{Methodology}

The paper is a subjective contextual analysis research. The description, sources of data, analysis of data, validation and reliability are given below. Third party logistics provider and use of information and communication technology for strategic logistics communication and also logistics management and significance are the key words for this paper. Hence, the reviewed literature introduces four subjects: logistics Planning, features of a powerful communication process for logistics, advanced information system, third-party logistics, and SaaS Software.The significance of assessing the logistics strategy in corresponding with any remaining business contemplation and market influences alongside the developing internationalization is created as a standard methodology. The role of information technology and data innovation for improvement and recreation is demonstrated to be as yet a significant piece of the interaction.(Berelson, 1952) The basic model reason is - (or the market competition) shape the detailing and execution of a company's methodology (at organizations and integration levels) and its authoritative construction. Every one of the components in this model is portrayed by various measurements. (Jing Jiang, 2012) Our contention is that these new assembling procedures and hierarchical structures won't be really fruitful if not for the improvement of enterprise-wide logistics practices and frameworks. This idea of enterprise-wide logistics is described by the joining of logistics exercises both inside and between deliberately adjusted associations containing the general endeavor.

\section{RQ1 : For What Reason is Communication Significant for Logistics?}

Logistics can coordinate with strategy and structure to furnish a manufacturing company with an upper hand in the present requesting market climate. However, logistics has, previously, been viewed as a barely characterized practical movement worried about errands like transportation, warehousing, stock, and materials management. Changes in logistics abilities,

Innovations, and the executive's strategies have permitted logistics to turn into an essential component for incorporating and planning exercises across phases of an inventory network. (Hamilton, 2015) The thought of logistics as a particularly persuasive variable might be new or untested. We contend that as firms become less and less progressive, as they become increasingly more geologically scattered, and as clients become increasingly requesting, logistics 
can give an organizing job that will outfit a firm with an advantage. (Rushton \& Saw, 1992) Information exchange expects a huge part in making shrewd and swift coordination's the board interaction. It ensures that endeavors are done and moved from one feature the other reliably and right away.For instance, the outreach group needs logistics information to research orders that aredispatched, customer administration needs data to invigorate shipment whereabout, and the records region needs the information to examine transporter requesting. The obtaining bunch needs data from the logistics function when new shippers are to be utilized or old arrangements are normal for restoration. Different elements of the supply chain network likewise need to team up or speak with the logistics group to complete their work. (Kersten, Blecker, \& Ringle, 2015)

\section{RQ2 : What are Significant Aspect of Strategic Logistic Planning?}

There are three significant parts of vital logistics planning incorporate long-haul objectives and the methods and cycle for accomplishing those objectives. (ALLEN, 2021).

Long haul objectives: This incorporates your organization's upper hand, consumer loyalty, and the supply chain board.

Means: The techniques for accomplishing your drawn-out aims join passing on worth and customer support.

Interaction: The cycle for achieving your association's drawn-out goals incorporates how one will design their logistics framework, similarly as expecting and administering change and linking each part of their logistics system to the association's general business targets. A strategic communication logistics plan commonly covers at least five years in an organization. On a more basic level, a strategic logistics communication plan ought to incorporate the accompanying components:

- An outline of logistics methodology overall terms and also how it identifies with other business capacities.

- Logistics goals and how they identify with cost and administration for the item and the client.

- Complete description of each and every strategy that will uphold the large essential logistics policies. These methodologies ought to incorporate stock and warehousing, request handling and satisfaction, transportation, and client care.

- A breakdown of these calculated or operational arrangement including costs for execution, timing, and their effect on other business capacities and the business overall.

- Estimation of prerequisites for the labor force, capital, and some other essential resources.

- Estimates of prerequisites for the labor force, capital, and some other essential resources.

- A business impacts investigation that subtleties expected effects on benefits, client support, and other business capacities.

- Adjusting your logistics objectives to more extensive business destinations is a very important segment of a compelling logistics system.

\section{RQ3: What are Features of a Powerful Communication Process for Logistics?}

Must provide clear timetables and it has to give clear timetables: The course or conveyance of chances for getting the response or the undertaking being appointed has to be unmistakably referenced in the communication. This will help the collector assemble data, design strategies, and carry out the need referenced in the communication message and stay away from superfluous deferrals. (Logistics, 2019)

Urgency must be conveyed appropriately. Various executives are prone to check every one of 
their messages as" earnest" to ensure that it stands out enough to be noticed by the authority. While this preparation is unprecedented to ensure that huge and crucial messages don't get missed, notwithstanding, now if all correspondence is crucial, focusing on endeavors gets hard. In same manner it debilitates the significance of the message. In such cases, the recipients take up the project in the need that they accept is right. Consequently, it is important to just check communication or undertakings that are the main concern as critical and not all correspondence. (Logistics, 2019)

\section{Transparency and Reliability}

Interdepartmental struggles, hierarchical governmental concerns, and relentless rivalry urge representatives to keep data from their associates or partners. This makes doubt, tumult, and disarray which thus influences the execution of projects or tasks. It is hence significant that the culture of organization grows clear communication and also sharing of dependable data.

\section{Must be in Real-Time}

The Logistics function is a high-speed capacity and information exchange moreover ought to be also quick. Consequently, information like a change of load rates, stacking records, customer orders, and so on. ought to be affirmed and moved to the accompanying person when has been gotten. Beside these things, questions asked identified with a task or interaction should be tended to quickly or the beneficiary should in any occasion give a schedule by when the sender may expect a reply.

\section{Incorporation of Technology}

Presently in this advanced age, basically getting written correspondence right isn't adequate to allow the productive execution of attractive methodologies. Affiliations should similarly consolidate the head ways, back-end systems, and cycles that are used by different workplaces to ensure that information streams reliably and without manual mediation beginning with one capacity then onto the following.

\section{Must Follow the 3 C'}

A clear, consistent, and concise message is an indication of amazing correspondence. A sensible message makes it possible that there is no obscurity in what ought to be passed on. Conciseness make certain that the message is brief yet joins amazingly critical information. Likewise, consistency in language, plan, and technique for movement ensures that the beneficiary doesn't lounge around in understanding the message.

\section{Incorporation of Technology}

Progressed data framework just as third-party logistics are elements of logistics administrations. As Bowersox and Closs (1996) recognized that, lately the elements of logistics administrations have extended from promoting and production to warehousing, transportation exercises, buying, dispersion, stock the executives, bundling, and client administrations, which summed up the logistics administrations coordinated.

Presently in current age, basically getting the written correspondence right isn't adequate to make sure the productive execution of attractive methodologies. Affiliations should similarly consolidate the headways, backend systems, and cycles that are used by different workplaces to ensure that information streams reliably and without manual mediation beginning with one capacity then onto the following.

For logistics which is a firmly related to data exchange, this joining is exceptionally pivotal. It will help to reduce manual data entry, delays in light of wrong system areas, and speed up the entire cycle. Automated records of the general large number of trades or determined activities 
will similarly simplify it to get reports, analyze execution, find oddities, and standardize the connection across different regions and dealers. When arranging or buying advancement or reappropriating the communication to a vendor, it is crucial to understand if this development will really need to join with various structures that your affiliation uses effectively and at any cost. An association's strategic communication interaction can be finished just when all the above components are available and interlinked through the available technology.

\section{The impact of Communication and Information Technology on Logistics}

The advancement in the field of information and communication technology has effectively affected numerous ventures particularly in the field of innovation. The utilization of PCs, the web, and data correspondence frameworks can be seen in pretty much every movement in the logistic business-like transportation, warehousing, request preparing, material administration, and obtainment. ICT has been elevated as a way to advance logistics competitiveness. It is one of only a handful few elements which has been demonstrated to have the capacity of expanding logistic skill and diminishing its expense all the while. The use of ICT in logistics management is not a new concept anymore idea any longer, it lets ongoing/online data correspondence and information trade through the whole activity chains.

Moreover, because of the far-reaching selection of the production network by transporters, transport suppliers are progressively needed to offer worldwide logistics administration bundles to more readily fulfill client needs. Information and Communication advancements (ICT) assume a critical part in this cycle, guaranteeing the linkages between chain members just as a more compelling control of time, cost, and nature of the help delivered. The individuals from the supply chain network are feeling the pressure to accomplish productivity, administration, and most importantly, to make their business beneficial. Logistics administrators are quickly receiving the most fitting advances to their cycles, consequently are being able to adjust to the new serious climate.

We are confronting general public heath crises where residents are progressively worried about wellbeing, health and food security, and where organizations see as significant, they need for their business insight frameworks and natural vehicle, to add to keeping a maintainable environment and climate, as it is progressively harmed.

ICTs in this way influence the value chain of organizations, improving the effectiveness of various exercises and permitting coordination of such exercises (Berumen and Arriaza, 2008). In any case, to exploit ICTs ideally, it is essential that organizations overhaul their cycles, figure out how to utilize them, and adjust to the new circumstance, aside from make substantial and theoretical interests in the organization. (Espinosa, 2016)

\section{Third-Party Logistics (3PL)}

Third-party logistics suppliers are organizations that offer total or halfway logistics administrations for their clients (R.Rajesha, S.Pugazhendhib, K.Ganeshc, YvesDucqd, \& Kohe, 2012). Through long stretches of improvement, 3PL supplier is acknowledged by the greater part of the organizations. There are reviews done by Lieb and Miller (2002) of which uncovered that 77percent of Fortune 500 producers utilize numerous outsider logistics suppliers for different sorts of administrations. Furthermore, among those organizations that utilizing outsider logistics, half of them have been utilizing the administrations for over 5 years. (Lieb \& Miller, 2010) Third-party logistics is a system that permits you to reevaluate operational logistics function from the warehouse, completely through to the delivery, and at last empowers you to zero in on different pieces of your business. 3PL a moderately new industry has acquired gain since the rise of the worldwide market and the Web, specifically in electronic business (online business/ecommerce). Worldwide serious ness puts more tension on organizations to improve their 
conveyance execution of items and administrations to clients. With an end goal to improve the nature of conveyance administration, organizations have re-appropriated their logistics administrations, including pressing, warehousing (stock administration) and transportation of merchandise to clients.Communication assumes a significant part in integrating the exercises along the logistics value chain. Data advancements, for example, electronic information exchange (EDI), the Web, Internet (WWW) and online business have contributed extraordinarily to improving correspondence with accomplices in the logistics chain.Utilizing a Third-party logistics provider offers loads of benefits. The greatest is that by giving over this logistics, one can zero in on different parts of the business-like deals, advertising, and item advancement. Reappropriating Third-party logistics leaves you with additional time and assets. Here are a couple of different benefits:

- Third-party logistics have more influence with cargo organizations than individual transporters do. Working with transporters in the interest of numerous clients, 3PLs can arrange valuing dependent on volume and request recurrence. Utilizing a 3PL to deal with all or a piece of your store network additionally gives you the opportunity to put resources into other key zones to develop constantly your business. (QuickBooks commerce, n.d.)

- Most organizations experience variances sought after consistently. Utilizing a 3PL permits you to oversee pinnacles and box all the more viably without focusing on capital especially, when you don't have to.

- Give a superior client experience: Clients expect following day or same-day delivery as standard. Utilizing an outsider logistics supplier permits you to offer quick delivery regardless of where the request is being sent, because of approaching the 3PL's wide dispersion organization.

- Test new business sectors: With a worldwide 3PL, you have the adaptability to try things out in new business sectors without focusing on any significant speculations like your own warehousing space or staff.

- Alleviate hazard: Transportation deferrals can and do occur for various reasons. At the point when unanticipated conditions spring up, a Third-party logistics is liable for making substitute plans to satisfy your orders as fast as could be expected. You will additionally be ensured in case of harm or loss of merchandise

- Gain moment ability and information in the field. Particularly in case you're simply beginning, who better to deal with your logistics than an organization that has some expertise in them? Satisfaction, warehousing, and delivery accompany significant difficulties of their own, so giving it off to the specialists can truly have an effect in the manner you work - and it leaves you to zero in on expanding your general worth to your clients.

- Understand international logistics. In case you are selling universally, 3PLs can deal with documentation, customs, obligations, and different issues that surface at the boundaries that can postpone your shipments and that can result in significant expenses if not done completely. Additionally, you can save time attempting to work-out confounded principles relating to various nations.

\section{Finding and Conclusion}

To sum up, logistics executives is a system for organizations since it improves rivalry and accomplishes enhancements in the benefit of them. Because of the presentation of new data and communication innovation (ICT), logistics the executives get incorporated into the general administration of the organization, bringing about a progression of data between various cycles and entertainers associated with the inventory network.

The presentation of ICT and the exceptional innovative unrest have established another serious climate, in view of the globalization of the economy and solid rivalry. Given this climate, 
organizations should confront getting by in their areas, since it influences their worth chain.Consequently, associations should update their cycles, figure out how to utilize ICT and ventures both unmistakable and theoretical, to adjust to this new circumstance is a system for organizations, since it improves rivalry and accomplish enhancements in the benefit of them. On account of the presentation of new data and correspondence innovation (ICT), Logistics system gets incorporated into the general administration of the organization, bringing about a progression of data between various cycles and entertainers associated with the store network. The presentation of ICT and the exceptional mechanical upheaval have made another serious climate, in light of the globalization of the economy and solid rivalry. Given this climate, organizations should confront making due in their areas, since it influences their worth chain.

Hence, associations should overhaul their measures, figure out how to utilize ICT and speculations both unmistakable and elusive, to adjust to this new circumstance.organizations, since it improves rivalry and accomplish enhancements in the benefit of them.

\section{References}

ALLEN, W. (2021, Febraury 22). 50 expert tips on logistics planning and strategy. Retrieved from 6 river system: https://6river.com/logistics-planning-and-strategy-tips/

Berelson, B. (1952). Content analysis in communication research. Free Press.

Chan, P. Y., Shi, X., \& Wang, Y. (2007). A Theoretical and Strategic Framework for Information Systems

Adoption in Supply Chain Management. Pacific Asia Conference on Information Systems. Aukland, New Zealand: PACIS.

Christopher, M. (1989). The logistics approach. Director, Vol. 43 No. 1, 9-66.

Espinosa, C. M. (2016). Information and communication technology in logistic processes of the companies. Universitat.

Fawcett, S., \& Fawcett, S. (1995). Integrating logistics, operations and purchasing. International Journal of Physical Distribution \& Logistics Management, Vol. 25, No, 5, 24-42.

Hamilton, B. A. (2015). Logistics Community of Interest Strategic and Communication Plan. United States Marine Corps; Logistics Community of Interest.

Hill, S. (1994). Want better customer service? Think logistically. Manufacturing systems, Vol. 12 No. 3.

Jing Jiang, R. W. (2012). Influences of culture and market convergence on the international advertising strategies of multinational corporations in North America, Europe and Asia. International Marketing Review.

Johnson, G., Whittington, R., \& Scholes, K. (2009). Fundamentals of Strategy. Prentice Hall.

Kersten, W., Blecker, T., \& Ringle, C. M. (2015). Innovations and Strategies for Logistics and Supply Chains: Technologies, Business Models and Risk Management . Proceedings of the Hamburg International Conference of Logistics (HICL) No. 20.

LaLonde, B., \& Masters, J. (1995). A survey of computer applications and practices in transportantion and distribution. International Journal of Physical Distribution \& Logistics Management, Vol. 25, No, 4,

12-21.

Lieb, R., \& Miller, J. (2010). The Use of Third-party Logistics Services by Large US Manufacturers, The 2000 Survey. International Journal of Logistics Research and Applications, 1-12.

Logistics, B. (2019, Febraury 28). How to Build an Effective Logistics Communication Process . Retrieved from Blue Grace: https://blog.mybluegrace.com/bluegrace-logistics/how-tobuild-an-effective-logistics-communication-process/QuickBooks commerce. (n.d.). Retrieved from What's 3PL?: https://www.tradegecko.com/supply-chainmanagement/what-is-3pl

R.Rajesha, S.Pugazhendhib, K.Ganeshc, YvesDucqd, \& Kohe, S. (2012). Generic balanced scorecard framework for third party logistics service provider. International Journal of 
Production Economics, Volume 140, Issue 1, , 269-282.

Richardson H.L. (1995). Logistics help for the challenged. Transportation \& Distribution Vol. 36 No. 1, 4-60.

Rushton, A., \& Saw, R. (1992). A methodology for logistics strategy planning. The International Journal of Logistics Management, Vol. 3 No. 1, 46- 